Erratum

\title{
Toward a Unified Theory of Muscle Contraction. II: Predictions with the Mean-Field Approximation
}

\author{
D. A. SMith ${ }^{1,2}$ and S. M. Mijailovich ${ }^{3}$ \\ ${ }^{1}$ Department of Physiology, Monash University, Clayton, VIC 3800, Australia; ${ }^{2}$ Department of Zoology, Latrobe University, \\ Bundoora, VIC 3083, Australia; and ${ }^{3}$ Harvard School of Public Health, Boston, MA, USA
}

(Published online 2 October 2008)

\section{Erratum to: Annals of Biomedical Engineering DOI: $10.1007 /$ s10439-008-9514-z}

Page 1360, last paragraph, next-to-last sentence: replace 'at $v=0-0.701$ at' by 'at $v=0$ to 0.701 at'
Page 1362, 3rd paragraph, sixth sentence:

replace 'at $x=0-49 \mathrm{~s}^{-1}$ at' by 'at $x=0$ to $49 \mathrm{~s}^{-1}$ at'

The online version of the original article can be found under doi: 10.1007/s10439-008-9514-Z.

Address correspondence to D. A. Smith, Department of Zoology, Latrobe University, Bundoora, VIC 3083, Australia. Electronic mail: David.Smith@1atrobe.edu.au 